\title{
A Cultura permeando os sentimentos e as reações frente à dor
}

\author{
CULTURE PERMEATING THE FEELINGS AND THE REACTIONS IN THE FACE OF PAIN
}

LA CULTURA PERMEANDO LOS SENTIMENTOS Y LAS REACCIONES FRENTE AL DOLOR

\section{Maria de Lourdes Denardin Budó1, Daiana Nicolini², Darielli Gindri Resta ${ }^{3}$, Emanoeli Büttenbender ${ }^{4}$, Michele Camponogara Pippi ${ }^{5}$, Lúcia Beatriz Ressel ${ }^{6}$}

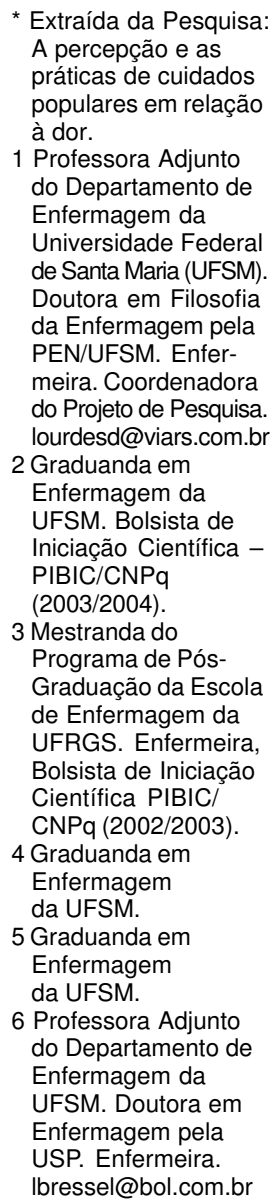

1 Professora Adjunto do Departamento de Enfermagem da Universidade Federal de Santa Maria (UFSM). Doutora em Filosofia da Enfermagem pela PEN/UFSM. Enfermeira. Coordenadora do Projeto de Pesquisa. lourdesd@viars.com.br

\begin{abstract}
RESUMO
Este estudo descreve a percepção e os significados da dor em adultos usuários do SUS. A população compreendeu 60 pacientes que buscaram o serviço no período. A pesquisa foi do tipo exploratório-descritiva, cujos dados foram coletados com entrevista semi-estruturada e analisados qualitativamente, constituindo temas que emergiram, sendo agrupados por categorias. Evidenciou-se que "o significado da dor" revelou o predomínio do entendimento da dor como uma questão física; apontou a dor relacionada também a questões emocionais e sentimentais, religiosas e humanas. "A reação de homens e mulheres frente à dor" é percebida diferentemente conforme o sexo feminino e masculino. Em "como você se sente nas situações em que tem dor?", as respostas variaram entre afetivas, cognitivas e comportamentais.
\end{abstract}

\section{DESCRITORES \\ Dor/etnologia. \\ Medição da dor/enfermagem. \\ Pacientes. \\ Sistema Único de Saúde.}

\section{ABSTRACT}

This study describes the perception of pain and the meanings it has for adults who use the Brazilian public health system, the Sistema Único de Saúde (SUS). The sample was comprised of 60 patients who sought the service in the period. This is a descriptiveexplanatory research whose data were collected through semistructured interviews and evaluated qualitatively. The emerging themes were grouped into categories. It was observed that "the meaning of pain" revealed the preponderance of the comprehension of pain as a physical matter. It also showed that pain is related to emotional, sentimental, religious and human circumstances as well. "The reaction of men and women in the face of pain" is perceived differently according to the gender. In questions such as "How do you feel when you are in pain?" the answers varied between affective, cognitive and behavioral.

\section{KEY WORDS}

Pain/etnology.

Pain measurement/nursing.

Patients.

National Health System (BR).

\section{RESUMEN}

Em este estudio se describe la percepción y los significados del dolor en adultos usuarios del Sistema Único de Salud (SUS). La población comprendió 60 pacientes que buscaron el servicio en el período. La investigación fue de tipo descriptivo exploratorio, cuyos datos fueron recolectados con una entrevista semi-estructurada y analizados cualitativamente, constituyendo temas que emergieron siendo agrupados por categorías. Se evidenció que "el significado del dolor" reveló el predominio del entendimiento del dolor como una cuestión física; apuntó el dolor relacionado también a cuestiones emocionales y sentimentales, religiosas y humanas. "La reacción de hombres y mujeres frente al dolor" es percibida de manera diferente conforme el sexo femenino y masculino. En "cómo se siente en situaciones en que tiene dolor?", las respuestas variaron entre afectivas, cognitivas y de comportamiento.

\section{DESCRIPTORES}

Dolor/etnología.

Dimensión del dolor/enfermería. Pacientes.

Sistema Único de Salud (BR). 


\section{INTRODUÇÃO}

A cultura exerce grande influência em todos os aspectos da vida das pessoas, incluindo suas crenças, comportamentos, percepções, emoções, religião, estrutura familiar, linguagem, alimentação, vestuário, imagem corporal e, entre outras situações, exerce um poderoso efeito na tolerância ou não à dor. Isto pode ser constatado em situações nas quais estímulos, que produzem dor insuportável em uma pessoa, podem ser perfeitamente toleráveis por outra.

A cultura pode ser definida como um conjunto de teias e significados que o próprio homem teceu e na qual se encontra amarrado ${ }^{(1)}$. Constitui-se no conjunto de mecanismos de controle que governam o comportamento humano e, somando-se a isso, o ser humano é

o animal mais desesperadamente dependente de tais mecanismos de controle, extragenéticos, fora da pele, de tais programas culturais, para ordenar seu comportamento ${ }^{(1)}$

Isto demonstra o quanto a cultura influencia os diversos aspectos da vida humana, e que tudo isto é produzido pelo próprio homem, no decorrer de sua vida e de suas experiências.

Autores da área da antropologia ${ }^{(2-4)}$ apresentam uma nova concepção de cultura, que rejeita a visão integradora e unificadora, centrada na velha perspectiva de unidade cultural e de sociedade unitária, padronizada e integrada, que avança em perspectiva fluida e aponta para a desunidade do todo, para a desordem, para a particularidade, para o pluralismo, para o sincretismo, para a heterogeneidade, para a complexidade e para a diversidade cultural.

Os mesmos autores ${ }^{(2-4)}$ expõem a descontinuidade e as diferenças, que devem ser mostradas nos trabalhos que trazem uma abordagem cultural, possibilitando a expressão de divergências. Valorizam o indivíduo como sujeito de sua própria vivência e a contextualização na análise do estudo, promovendo um olhar dinâmico, progressivo, que admite contestação e rupturas nos trabalhos.

Isso significa entender a cultura numa nova ordem global, vale dizer, de forma mais ampla, dando espaço para as diferenças, inclusive para as antagônicas, expressarem-se num mesmo tempo e lugar. Denota se opor à rigidez, ao reducionismo, à limitação que a própria estética da vida pode querer impor. Mostra aceitar uma composição cultural múltipla, oriunda de diferentes modelos de vida social, que podem trazer e trazem conflitos, e não harmonia na existência comum. Significa ainda uma fusão de diferentes elementos culturais, mantendo a natureza original de cada $\mathrm{um}^{(3-4)}$.
Por outro lado, a cultura não pode ser avaliada isoladamente, mas como um componente de uma mistura complexa de influências que atuam na vida das pessoas ${ }^{(5)}$. Influências estas herdadas pelos indivíduos na sociedade em que vivem, e que evidenciam as formas pelas quais vêem o mundo e se relacionam com as outras pessoas de seu meio.

A dor é uma parte inseparável da vida cotidiana, sendo um dos sintomas mais presentes na prática dos profissionais de saúde. Em um estudo ${ }^{(6)}$ que analisou os conceitos de enfermeiros e médicos sobre dor e analgesia no trauma, constatou-se que a dor é um fenômeno subjetivo, podendo ser indicada e quantificada pela pessoa que a sente. Para avaliar a dor, os profissionais utilizavam como parâmetro o relato do paciente através de manifestações verbais ou outras.

A dor constitui-se em uma experiência privada e subjetiva, não resultando apenas de características de lesão tecidual, mas que integra também fatores emocionais e culturais individuais. A dor é elemento crucial para a proteção e a manutenção da vida, pois é sinal de algum dano, tem papel biológico fundamental e pode ser manifestada por dois tipos de reações ${ }^{(5)}$ : involuntária e voluntária. A reação involun-tária é instintiva, mas a reação voluntária à dor pode envolver outras pessoas e é in-fluenciada, além do fator biológico, por fatores sociais e culturais.

Cada cultura ou grupo social e, às vezes, até cada família, tem uma linguagem de sofrimento única e própria, que é um conjunto complexo de termos próprios por meio do qual os indivíduos enfermos ou infelizes fazem com que as outras pessoas se tornem cientes de seu sofrimento $^{(5)}$

Entende-se, assim, que existe uma forma de as pessoas comunicarem a dor, estando as mesmas intimamente ligadas a padrões culturais de valorização ou desvalorização e da exteriorização da resposta à dor e ao sofrimento. Esta exteriorização da dor é uma maneira de tornar a dor privada em dor pública e é determinada, principalmente, pela intensidade percebida da sensação dolorosa, isto é, a tolerância à dor.

\section{A tolerância à dor pode ser considerada como}

\section{a menor intensidade em que o estímulo passa a ser perce- bido como desconfortável a ponto de o indivíduo se retrair e/ou solicitar sua interrupção ${ }^{(7)}$.}

A tolerância à dor varia muito e está relacionada a fatores sensoriais (extensão e localização da lesão tecidual), a fatores genéticos, emocionais (medo, ansiedade, raiva), culturais (aprendizagem, experiências anteriores, significado simbólico da dor) e sociais. Diante da diversidade dos fatores envolvidos na expressão da dor, a sua tolerância varia muito entre os indivíduos. 
Além disso, a visão da dor pode ser muito diferente entre os profissionais de saúde e os pacientes. Alguns pacientes podem não se sentir doentes, se não sentirem dor, pois a sua sensação desprazerosa torna sempre implícita a sua associação com uma enfermidade. Por outro lado, para os profissionais, nem sempre a enfermidade é associada a alguma dor, como é o caso de alguns tumores indolores ${ }^{(8)}$.

Frente a essa multiplicidade de perspectivas da dor, dos diferentes fatores envolvidos na sua apreciação e percepção, a sua sensação pode variar muito entre as pessoas e precisa ser entendida pelos profissionais que trabalham nesta área.

Este artigo apresenta um recorte do projeto de pesquisa "A percepção e as práticas de cuidados populares em relação à dor", cujos objetivos foram os de conhecer a percepção e o significado da dor para os usuários do Sistema Único de Saúde (SUS) e detectar as práticas de cuidados relacionados à presença da dor em si mesmos e nos outros. A análise feita neste artigo refere-se à primeira parte do objetivo, que foi o de conhecer a percepção e o significado da dor para os usuários do Sistema Único de Saúde (SUS).

\section{METODOLOGIA}

\section{Universo empírico}

Este trabalho foi desenvolvido em uma unidade ambulatorial de um hospital público, federal, de referência regional e de ensino: Hospital Universitário de Santa Maria (HUSM) e em uma unidade básica de saúde do SUS, do município de Santa Maria - RS, Unidade Sanitária Kennedy (USK), tendo em vista serem estes campos de aulas práticas e de estágio supervisionado para os alunos do Curso de Enfermagem da Universidade Federal de Santa Maria (UFSM).

O Hospital Universitário de Santa Maria (HUSM) é um hospital-escola e um centro de referência na região centrooeste do Rio Grande do Sul, abrangendo 112 municípios que correspondem a seis coordenadorias regionais de saúde. Mantém atendimento primário, secundário e terciário, estando integrado ao SUS, fazendo parte do programa de regionalização e hierarquização da saúde como referência secundária e terciária.

O ambulatório ALA I do Hospital Universitário de Santa Maria localiza-se no andar térreo. Neste setor são atendidas pessoas que procuram o hospital para consultas, exames diagnósticos e tratamento. Existem neste serviço várias especialidades médicas, serviços de enfermagem, psicologia e nutrição.

A Unidade Sanitária Kennedy está localizada na Zona Norte da cidade de Santa Maria, abrangendo 18 vilas, quais sejam: Kennedy, Negrini, Brasília, Bela União, Salgado Fi- lho, São João, São Rafael, Caturrita, Nossa Senhora do Trabalho, Conceição, Brenner, Matadouro, Jane, Santana, Norte, do Carmo, Carolina e Vitória. Compreende uma população de aproximadamente trinta mil habitantes, sendo que esta área se caracteriza por altos índices de desemprego, criminalidade, desnutrição, doenças infecto-contagiosas, além da precariedade de saneamento básico e habitação.

Essa unidade sanitária conta com atendimento médico (clínicos gerais e especialistas) e equipe de enfermagem, desenvolvendo ações de saúde em atenção básica para adultos e crianças nos programas previstos pelo Ministério da Saúde. As ações na promoção da saúde do adulto englobam usuários portadores de distúrbios crônico-degenerativos, bem como doenças infecto-contagiosas.

Os participantes da pesquisa foram os usuários adultos das unidades anteriormente referidas que buscaram atendimento de saúde nestas unidades, no período de agosto de 2002 a janeiro de 2003 .

No HUSM, os entrevistados foram os pacientes que vieram para algum tipo de atendimento no ambulatório de adultos, especialmente nas áreas como reumatologia, angiologia, endocrinologia, enfermagem e outras, onde são mais comuns queixas de dor.

Na USK, participaram da pesquisa os pacientes que buscavam o atendimento no programa do adulto e demais serviços da unidade. Além destes, participaram, por intermédio de visitas domiciliárias, usuários que moravam nas proximidades da unidade.

Os critérios utilizados para a escolha dos usuários que fizeram parte do estudo foram os seguintes: ser paciente adulto, ter procurado atendimento no ambulatório do HUSM e da USK durante o período de coleta de dados, ou nas visitas domiciliárias e aceitar participar da pesquisa.

Fizeram parte do estudo 60 (sessenta) pacientes, sendo 34 (trinta e quatro) do HUSM e 26 (vinte e seis) da USK. O número de pessoas envolvidas na pesquisa foi limitado à exaustão dos dados.

\section{Coleta de dados}

Para o instrumento de coleta de dados foi utilizada a entrevista semi-estruturada. Entende-se que esta pode elucidar o problema de pesquisa e possibilitar o alcance dos objetivos propostos por este estudo. A entrevista constou de questões adaptadas a partir da proposta de Villarruel $^{(9)}$ para trabalhar com pessoas sobre dor, em uma vertente cultural do cuidado. Foram realizadas no ambulatório do HUSM e USK, em local previamente selecionado para esta atividade, antes ou após a realização do atendimento do usuário pelos profissionais, ou ainda em visitas domiciliárias. 
Para a realização da pesquisa, o projeto foi submetido ao Comitê de Ética em Pesquisa do Centro de Ciências da Saúde, da Universidade Federal de Santa Maria, sendo aprovado. Além disso, foi solicitado o consentimento da Direção do Hospital Universitário de Santa Maria, conforme as normativas deste hospital e da chefia de enfermagem da USK.

Foi elaborado, para os informantes do estudo, um Termo de Consentimento Livre e Esclarecido, apresentando os objetivos da pesquisa, a finalidade e os procedimentos a serem realizados, que foi assinado em duas vias pelos mesmos após concordarem em participar da pesquisa. Foi também garantida a liberdade de se retirarem em qualquer etapa do estudo, sem acarretar-lhes nenhum tipo de prejuízo, o que atende à Resolução 196/96 do Ministério da Saúde ${ }^{(10)}$.

Para a realização da entrevista, foi solicitada a gravação, com intuito de registrar integralmente as falas dos sujeitos, assegurando material rico e fidedigno para a análise. As entrevistas gravadas foram digitadas para sua análise posterior. Para preservar a confidencialidade dos dados dos informantes e os seus anonimatos, não foram mencionados os nomes dos pacientes em nenhuma etapa do relato da pesquisa.

\section{Análise dos dados}

O desenvolvimento da análise desta pesquisa ocorreu por meio da organização, leitura e discussão dos dados coletados. A análise foi constituída de três fases, ao abordar a análise temática ${ }^{(11)}$ : a pré-análise, a exploração do material e o tratamento dos resultados obtidos e a sua interpretação.

A pré-análise foi a fase em que o conjunto de dados obtidos foi organizado para uma análise mais aprofundada posteriormente. Nesta etapa, foi realizada uma leitura flutuante do conjunto das comunicações obtidas nas entrevistas. Esta organização inicial foi realizada no momento em que foram registradas as mesmas. As informações organizadas constituíram um corpus para a continuidade da análise.

Com estes elementos em mãos, foi possível a exploração do material, buscando a classificação em categorias emergentes, isto é, êmicas ${ }^{(a)}$. Em algumas situações, utilizou-se a organização em categorias e subcategorias teóricas de estudos na área. Nesta fase, com idas e vindas ao material, na busca de significados e agrupamentos de dados, emergiram temas ou categorias que tiveram significado no contexto dos objetivos da pesquisa.

A terceira etapa, constituída pelo tratamento dos resultados obtidos e sua interpretação, foi o momento em que, a

\footnotetext{
(a) êmico: constituído pelo conhecimento do grupo estudado, de uma dada cultura, expresso na sua lógica interna, em contraposição ao ético, que é o conhecimento do observador, representado por categorias teóricas ${ }^{(12)}$
}

partir da organização dos dados, buscou-se o seu significado. Nesta última fase, foram feitas interpretações a partir do marco teórico proposto, bem como inferências que poderiam esclarecer os achados da pesquisa. Esta análise permitiu a apreensão do caráter multidimensional dos fenômenos em sua manifestação natural, bem como favoreceu a possibilidade de se captar os significados da experiência vivenciada para compreender os indivíduos em seu contexto.

Mesmo tratando-se de pesquisa qualitativa, para que sua descrição evidencie as diferenças de pontos de vista entre os informantes, optou-se por se apresentar alguns dados numéricos, procurando trazer esclarecimentos consubstanciados no recorte do universo empírico estudado.

\section{APRESENTAÇÃOE DISCUSSÃO DOS RESULTADOS}

\section{Caracterização dos sujeitos da pesquisa}

O universo empírico constituiu-se de 60 (sessenta) indivíduos, moradores em vilas e bairros da periferia urbana de Santa Maria (USK). A população que busca o HUSM é também constituída de moradores da periferia urbana e rural de Santa Maria e municípios da região.

Os dados a seguir relatados se referem ao perfil dos participantes da pesquisa, sendo caracterizados quanto ao sexo, faixa etária, estado civil, escolaridade e religião, elementos fundamentais para a compreensão dos dados.

Do total das sessenta entrevistas realizadas no HUSM e na USK, pôde-se observar que quarenta foram respondidas por mulheres, caracterizando a população feminina como a que mais procurou os serviços de saúde, neste período. Com relação à faixa etária, a maioria dos entrevistados no HUSM apresentavam entre 41 a 60 anos; já, na USK, apresentavam 61 a 80 anos de idade. No que se refere ao estado civil, a maioria era casada. Quanto à escolaridade, a maioria possuía o primeiro grau incompleto. Com relação à religião, a grande maioria dos entrevistados era católica.

Outro dado bastante relevante da pesquisa diz respeito ao fato de que cerca da metade dos entrevistados residiam com a família ampliada, ou seja mãe, pai, filhos, avós, tios, sobrinhos ou outros membros.

\section{A percepção e o significado da dor}

Com a análise das questões relacionadas à percepção e ao significado da dor, evidenciaram-se as categorias significado da dor, reação de homens e mulheres diante da dor e sentimentos frente à dor, descritas a seguir. 


\section{Significado da dor}

Esta categoria sintetiza alguns aspectos relacionados às crenças, aos modos de expressão e à avaliação da dor pelas pessoas entrevistadas, considerando-se uma perspectiva cultural.

Durante as entrevistas, quando eram feitas as seguintes perguntas: o que você pensa que causou a dor? e nos costumes de sua família (cultura, etnia) o que significa ter dor? e como é percebida a dor?, houve uma série de respostas que foram agrupadas em subcategorias, como $a$ dor como uma questão física; dor relacionada a questões emocionais e sentimentais; dor como uma questão religiosa $e$ dor como uma condição humana.

Entre as respostas apresentadas, a dor como uma questão física, corresponde à maioria das respostas das pessoas entrevistadas, tanto no HUSM como na USK. Na seqüência, foram evidenciadas a dor relacionada a questões emocionais e sentimentais, seguida pelas subcategorias dor como uma questão religiosa e, sendo menos citada, a dor como uma condição humana.

Os entrevistados que atribuíram a causa da dor como uma questão física relacionaram a dor como um sinal de alerta de que algo estava ocorrendo errado com a integridade e a normalidade do seu organismo, o que se constatou em respostas como

... o corpo que está falhando...;

... a dor está relacionada com a fisiologia do corpo...;

... a dor é por causa da infecção do pé.

Essas opiniões exemplificam a relação da dor com algumas doenças específicas, falências progressivas do organismo, ou dor por esforço repetitivo. É uma visão centrada especificamente sobre o organismo, sendo este interpretado como uma máquina em um plano extremamente segmentado, que sinaliza quando algo não está bem e precisa de $\operatorname{reparos}^{(13)}$.

Um dos conceitos de dor mais aceitos atualmente é aquele que compreende três componentes: o sensitivo-discriminativo (sensação física), o afetivo-motivacional (sensação emocional) e o cognitivo-avaliativo (pensamento) ${ }^{(7)}$. As autoras descrevem a dor como uma informação transmitida da periferia para o Sistema Nervoso Central, que interage com fatores emocionais e culturais que podem interferir e modificar a percepção da informação inicial. A partir disto, pode-se entender que a percepção dolorosa é um conjunto de combinações e interpretação de fatores individuais, tais como humor, experiências anteriores, crenças, atitudes, conhecimentos e significados simbólicos atribuídos a queixas dolorosas. No entanto, para as pessoas entrevistadas, não há uma integração de fatores como os descritos pelas autoras, sendo a dor apresentada como uma percepção segmentada.
Pode-se inferir que esta postura reflete o modelo biomédico ainda persistente no setor profissional, no qual a assistência à saúde é centrada no biológico. Isto tem influenciado o saber popular, pois as pessoas, ao se aproximarem de algum serviço deste setor, adaptam sua linguagem ao ambiente onde se encontram. Esta adaptação do saber popular ao saber profissional foi também encontrado num estudo ${ }^{(14)}$ realizado numa comunidade rural, no qual foi constado que há associação de percepções e cuidados em saúde aprendidos por intermédio da tradição familiar e do convívio com o sistema profissional.

Também é possível evidenciar essas afirmações na prática diária dos profissionais da saúde, pois, ao se relacionarem com as pessoas na comunidade, os mesmos encontram opiniões bastante fragmentadas que não permitem retratar o contexto onde vivem. As pessoas, ao procurarem os serviços de saúde, manifestam a sua doença ou a sua dor de maneira isolada, demonstrando forte influência cultural do ambiente onde são assistidas. O hospital e a unidade de saúde são ambientes que propiciam a fragmentação entre organismo e contexto sociocultural das pessoas, pois as mesmas, ao se dirigirem a estes locais, evidenciam a necessidade de suprir a sua dor naquele momento.

Outra subcategoria encontrada foi a dor relacionada a questões emocionais e sentimentais, isto é, a sensação dolorosa associada ao psiquismo do indivíduo, ao nervosismo, a tensões emocionais do cotidiano, à carência afetiva, à personalidade, dentre outros fatores, como mostram algumas expressões usadas pelos entrevistados:

a dor quem faz é a pessoa, a consciência da gente;

a dor é psicológica;

vem dos nervos;

se a pessoa está nervosa afeta tanta coisa... .

Muitas culturas relacionam a dor ao estado psicológico da pessoa, o que muitas vezes pode determinar a intensidade da dor e o seu grau de aceitação pelo indivíduo. Neste aspecto, os profissionais de saúde, durante a assistência, precisam estar atentos e trabalhar também com as questões emocionais ou psicológicas do indivíduo, para conseguirem, posteriormente, prestar os cuidados adequados ao cliente. Esta integração entre sofrimento físico e mental tem sido referida por autores ${ }^{(15)}$ que nos alertam sobre a importância de valorizar as queixas de dor e do sofrimento crônico, já que estes podem levar à depressão e a pensamentos suicidas.

Algumas respostas dos entrevistados sobre o significado e a percepção da dor relacionaram-se à fé e/ou à religião, constituindo a subcategoria dor como uma questão religiosa. Isto pôde ser identificado nas seguintes falas:

acredito que às vezes a gente sente dor devido à vontade de Deus; 
Deus é tudo para mim; supero a dor através da minha fé em Deus.

Em grande parte das culturas, a dor é considerada como uma das possíveis fatalidades que podem ocorrer a seus membros. Em busca de respostas ou explicações, algumas pessoas não se baseiam apenas na ciência, mas também nas religiões, nas crenças e nos valores morais de sua cultura. As religiões moldam as percepções que os indivíduos têm de si mesmos e também de suas respostas à dor ${ }^{(7)}$.

A dor também foi evidenciada como punição e purificação da alma, ou castigo, com as seguintes respostas:

se a gente andar direitinho no caminho de Deus, a gente não sente dor. Devemos ser obedientes a ele e daí se tem tudo do Pai;

dor pode ser por falta de fé;

perdi a visão por castigo de Deus, pois assistia TV ao invés de trabalhar;

... às vezes tenho um pouco de pecado.

A fé religiosa pode auxiliar muito na tolerância à dor, mas pode também levar o indivíduo a interpretar a dor como uma punição e procurar em preces e rituais o perdão para possíveis erros ${ }^{(7)}$. Isto se deve, provavelmente, à forte influência religiosa do cristianismo, no qual a dor passou a ser valorizada como uma forma de manifestação da fé a partir do século doze ${ }^{(15)}$.

Todos os participantes da pesquisa informaram terem uma religião, sendo que onze deles vincularam de alguma forma a sua dor à religiosidade. Alguns estudos ${ }^{(7)}$ apontam, entre outras possibilidades, a vivência da dor como meio de purificar a alma. Determinados grupos religiosos podem se comportar de maneiras diferentes diante da dor e ainda podem mudar significativamente seus padrões de comportamento de acordo com sua associação a diferentes grupos. Em estudo realizado ${ }^{(16)}$ sobre o significado da dor para pacientes cirúrgicos, foram encontrados aspectos culturais comuns nas falas dos pacientes e foram relacionados a algo de errado com o corpo e à crença de que a dor é uma punição de Deus.

Na subcategoria dor como uma condição humana, algumas pessoas correlacionaram a dor como uma percepção física normal, algo que faz parte da vida ou do destino de cada um, demonstrando uma opinião totalmente passiva e conformista frente a uma situação dolorosa. As respostas foram

acho que todos nós passamos, tem um dia que vai sentir, não é castigo;

representa que é destino, que a pessoa trouxe no dia que nasceu, que tem que atravessar;

é próprio da pessoa sentir dor, todo mundo tem.
A dor ainda foi relacionada com hábitos de vida da pessoa, por exemplo: acho que a alimentação dos turcos é muito forte e isto influencia, constituindo a subcategoria dor relacionada aos hábitos de vida.

Quando questionados sobre o que pensavam seus familiares sobre a dor, suas causas e cuidados, os participantes referiram ser a dor uma decorrência da doença, como conseqüência natural do processo patológico. Outros referiram ser a dor causada por descuido com a saúde. Este descuido pode estar relacionado à alimentação inadequada, principalmente por seu consumo em excesso; pelos vícios como tabagismo e etilismo ou por atividade física intensa no trabalho. Outros apontaram o nervosismo como elemento causador da dor, com a resposta: eles me dizem que isto (a dor) é dos nervos, que os nervos judiam muito das pessoas. Por outro lado, alguns entrevistados manifestaram que os familiares vêem a dor como algo natural, sendo um fato normal da vida. Quanto ao cuidado que se deve ter em relação à dor, referiram ser necessário coragem para enfrentá-la, suportando-a e tomando a medicação de acordo com o prescrito. Estas respostas, em relação ao que pensam seus familiares, são semelhantes e confirmam o que os entrevistados, em sua maioria, referiram sobre as causas da dor.

\section{Reação de homens e mulheres diante da dor}

Para se conhecer se existia diferença de opinião sobre a reação de homens e mulheres em relação à dor, perguntouse como você observa a reação de homens e mulheres diante da dor? As respostas foram agrupadas de acordo com as seguintes subcategorias: os homens são mais sensíveis; as mulheres são mais sensíveis; não há diferença entre o pensamento dos dois sexos. Na discussão destas subcategorias, não se tem a intenção de se aprofundar a reflexão sobre gênero, mas evidenciar algumas diferenças de percepção em relação ao sexo, pois isto é fundamental para o cuidado de enfermagem.

Dentre as mulheres entrevistadas, $80 \%$ relataram acreditar serem os homens mais sensíveis aos estímulos dolorosos. A seguir, apresentam-se respostas que confirmam esta afirmação:

o homem se queixa mais fácil, a mulher não, ela é forte;

o homem se dá uma gripe ou uma dor de cabeça, já está na cama;

o meu marido é vil;

a mulher suporta mais que o homem, em função da cultura que nos passam, temos que suportar a dor desde menina, as cólicas, as dores do parto e nós vamos fazendo aquela bagagem de suportar a dor;

a mulher tem que se preocupar com os filhos, netos e com o serviço da casa. 
Os trechos anteriores, extraídos exclusivamente de entrevistas realizadas com mulheres, demonstram que estas acreditam que os homens são mais sensíveis à dor. A mulher passa pela dor do parto, das cólicas menstruais, que são dores exclusivas delas, e elas relatam que os homens não têm a dimensão destas dores, por isso são tão pouco resistentes. Por outro lado, as mulheres são criadas para referirem suas dores e seus sofrimentos com mais emoção do que os homens ${ }^{(5)}$.

Dos homens entrevistados, $37 \%$ afirmaram não haver diferença entre homens e mulheres na reação diante da dor. Apresentam-se a seguir algumas das respostas: às vezes um sente mais, outro menos, depende; é quase igual à pessoa, tendofé, na hora é curada. Também entre os homens, 31,6\% dizem serem eles os mais sensíveis à dor.

Diante do sofrimento e da dor, espera-se que os homens tenham uma postura desprovida de emoções. Este mesmo autor também se refere sobre a dor privada sem demonstrações verbais ou não-verbais, como um comportamento esperado por parte dos homens, especialmente dos mais jovens. Isto vem ao encontro de uma frase encontrada nas entrevistas: eu acho que o homem guarda mais a dor para ele, a mulher fala.

Homens e mulheres são educados para terem expectativas diferentes em relação à vida, principalmente no que diz respeito às emoções, dentre elas a dor. Frente a esta análise, pode-se constatar que os métodos de educação infantil aplicados a meninos e meninas influenciam ativamente a formação de condutas e expectativas diante de reações à dor, que irão refletir na idade adulta.

Uma questão que precisa ser mais bem esclarecida, nesse caso, é que, mesmo sendo as mulheres consideradas mais resistentes, o número delas é maior na busca de assistência à saúde. Isto pode ser percebido pelo número de pessoas entrevistadas neste estudo, em que a quantidade de mulheres é o dobro (40) em relação aos homens (20), pois eram as que estavam nos locais de coleta de dados, no período do estudo.

\section{Sentimentos frente à dor}

Quando os clientes foram questionados como você se sente nas situações em que tem dor?, as respostas foram bastante variadas. Para agrupá-las, utilizou-se a classificação que chama a atenção para a importância do reconhecimento das diferentes respostas frente à dor crônica ${ }^{(17)}$. Para este autor, as respostas frente à dor podem ser afetivas, cognitivas e comportamentais. Entre as respostas afetivas, encontraram-se sentimentos como depressão, nervosismo, ansiedade, tristeza, desespero, entre outras, como pode ser constatado nas seguintes falas:

...a gente fica assim meio triste...;

... a gente fica muito nervosa, deprimida...;
... terrível, dá vontade de espernear....

Outras respostas foram agrupadas em respostas cognitivas, como uma forma de enfrentamento da dor:

procuro me acalmar...;

tem que suportar e ir levando a vida...;

... procuro tomar um analgésico...;

... procuro a graça de Deus... .

As respostas comportamentais representam uma reação individual à dor:

... eu tenho que chorar e desabafar...;

... fico muito chateada...;

... fico abatido e me preocupo com a dor....

Essa análise evidencia que a reação frente à dor é vinculada à cultura, influenciando os sentimentos das pessoas. Em conseqüência disto, estes sentimentos podem interferir, facilitando ou dificultando a adesão ao tratamento, a resposta terapêutica, a assistência prestada por toda a equipe de saúde e mesmo o relacionamento cliente-equipe.

\section{CONCLUSÕESE CONSIDERAÇÕES FINAIS}

No universo empírico representado por esta pesquisa, os significados atribuídos à dor estão apresentados na ordem em que foram mais citados. A dor emergiu como um significado vinculado à questão física, à questão emocional e sentimental, como uma questão religiosa, como uma condição humana e ligada a hábitos de vida.

Verificou-se, também, que existem diferenças nas reações frente à dor entre homens e mulheres. Assim, para as mulheres, os homens são mais sensíveis. Já os homens, embora relatem serem as mulheres mais resistentes à dor, também entendem que ambos são resistentes e sensíveis; a diferença, para eles, está na demonstração exteriorizada muito mais pelas mulheres.

No que se refere aos sentimentos evidenciados pelas pessoas participantes da pesquisa em situação de dor, encontraram-se respostas na esfera afetiva, cognitiva e comportamental que influenciaram a postura de como as pessoas encaram e efetivam o tratamento.

Constatou-se, com a análise das entrevistas realizadas, que os indivíduos entrevistados sofrem forte influência cultural nas reações e nos sentimentos em relação à dor, confirmando a importância do tema pesquisado para os profissionais de saúde. Os profissionais de enfermagem, muitas vezes, possuem dificuldade de entender e, conseqüentemente, respeitar a cultura privada dos usuários, subestimando ou supervalorizando sua manifestação frente à dor. 
Embora estes resultados restrinjam-se ao local onde foi realizada a pesquisa, são um indicativo para o trabalho da enfermagem. O nosso olhar evidenciou este ângulo, mas certamente outros olhares premiariam outros aspectos. Esta reflexão é entendida mais como expressão desta realidade, neste momento, com este grupo e menos, como uma verdade absoluta.

A enfermagem necessita realizar mudanças para trabalhar com as pessoas, respeitando as especificidades culturais locais e a diversidade cultural global. Ainda, precisa buscar explicações, entender, interpretar e predizer as práticas culturais de cuidado com pessoas que já se cuidam em situações de saúde ${ }^{(18)}$. Além disso, é fundamental que se perceba, que numa mesma sociedade aparentemente homogênea, encontram-se diferentes manifestações culturais, numa demonstração de que a diversidade cultural é muito mais evidente do que se pode perceber sem uma análise mais acurada ${ }^{(19)}$. Ao se analisar as entrevistas deste estudo,

\section{REFERÊNCIAS}

1. Geertz C. A interpretação das culturas. Rio de Janeiro: Livros Técnicos e Científicos; 1989.

2. Geertz C. Nova luz sobre a antropologia. Rio de Janeiro: Jorge Zahar; 2001.

3. Featherstone M. O desmanche da cultura: globalização, pósmodernismo e identidade. São Paulo: Studio Nobel; 1997.

4. Robertson R. Globalização: teoria social e cultura global. Petrópolis: Vozes; 2000.

5. Helman CG. Cultura, saúde e doença. $4^{\mathrm{a}}$ ed. Porto Alegre: Artmed; 2003.

6. Calil AM, Pimenta CAM. Conceitos de enfermeiros e médicos de um serviço de emergência sobre dor e analgesia no trauma. Rev Esc Enferm USP. 2005;39(3):325-32.

7. Pimenta CAM, Portnoi A. Dor e cultura. In: Carvalho MMMJ, organizador. Dor: um estudo multidisciplinar. São Paulo: Summus; 1999. p. 159-73.

8. Ferreira J. Semiologia do corpo. In: Leal OF, organizador. Corpo e significado: ensaios de antropologia social. $2^{\mathrm{a}}$ ed. Porto Alegre: UFRGS; 2001. p. 89-104.

9. Villarruel A. Cultural perspectives of pain. In: Leininger M. Transcultural nursing: concepts, theories, research \& practices. New York: McGraw-Hill; 1995. p. 263-77.

10. Conselho Nacional de Saúde. Resolução n. 196, de 10 de outubro de 1996. Dispõe sobre diretrizes e normas regulamentadoras de pesquisas envolvendo seres humanos. Bioética. 1996;4 (2 Supl):15-25 pôde-se averiguar esta diversidade de manifestações a respeito da dor, o que pode elucidar o entendimento do foco em estudo e influenciar a prática profissional.

Entende-se que estudar a dor na perspectiva cultural é de fundamental importância para os enfermeiros, pois estes possuem uma relação muito próxima no cuidado das pessoas, uma vez que são profissionais presentes de forma mais integral nas situações de doença dos indivíduos, juntamente com suas famílias. Portanto, o exercício de olhar um evento de saúde, no caso deste estudo -a dor-, sob a perspectiva cultural, faz o diferencial e possibilita realizar um cuidado mais humanizado. Neste sentido, a humanização do cuidado dá oportunidade às pessoas para demonstrarem seus sentimentos, percepções, crenças e valores manifestados pela visão de mundo que possuem. Dar expressão à diversidade, permitindo sua manifestação, pode trazer contribuições para o cuidado de enfermagem.

11. Minayo MCS. O desafio do conhecimento: pesquisa qualitativa em saúde. $8^{\text {a }}$ ed. São Paulo: Hucitec; 2004.

12. Victora CG, Knauth DR, Hassen MNA. Pesquisa qualitativa em saúde: uma introdução ao tema. Porto Alegre: Tomo Editorial; 2000 .

13. Polak YNS. A corporeidade como resgate do humano na enfermagem. Pelotas: UFPel; 1997.

14. Denardin ML. Cuidando e sendo cuidado: um modelo cultural de saúde em comunidade rural. In: Gonzales RMB, Beck CLC, Denardin ML. Cenários de cuidado. Santa Maria: Pallotti; 1999. p. $159-259$.

15. Essenfelder R. Dor altera personalidade e chega a provocar depressão [texto na Internet]. São Paulo; 2002. [citado 2004 jul. 20]. Disponível em: http://www1.folha.uol.com.br/folha/ treinamento/epidemiadador/.

16. Pereira APS, Zago MMF. As influências culturais na dor do paciente cirúrgico. Rev Esc Enferm USP. 1998;32(2):144-52.

17. Figueiró JAB. Aspectos psicológicos e psiquiátricos da experiência dolorosa. In: Carvalho MMMJ, organizador. Dor: um estudo multidisciplinar. São Paulo: Summus; 1999. p. 140-58.

18. Leininger M. Transcultural nursing: development, focus, importance, and historical development. In: Leininger $\mathrm{M}$. Transcultural nursing: concepts, theories, research \& practices. New York: McGraw-Hill; 1995. p. 3-34.

19. Cuche D. A noção de cultura nas ciências sociais. São Paulo: EDUSC; 1999.

Pesquisa financiada com bolsa de Iniciação Científica (PIBIC/CNPq) 